\title{
Mentoring Matters
}

\author{
Mentoring and Career Preparation in Internal Medicine Residency Training \\ Radhika A. Ramanan, MD, MPH, 1,2 William C. Taylor, MD, ${ }^{1,2}$ Roger B. Davis, ScD, ${ }^{1,2}$ \\ Russell S. Phillips, $M D^{1,2}$ \\ 'Division of General Medicine and Primary Care, Department of Medicine, Boston, MA, USA; ${ }^{2}$ The Shapiro Institute for Education, \\ Beth Israel Deaconess Medical Center, Harvard Medical School, Boston, MA, USA.
}

PURPOSE: Mentoring during the early stages of a career has been associated with high career satisfaction and may guide development of professional expertise. Little is known about mentoring experiences during residency training. Our purpose was to describe mentoring relationships among internal medicine residents, and to examine the relationship between mentoring and perceived career preparation.

SUBJECTS AND METHODS: We designed and administered a mailed survey to all interns and residents enrolled in the five independent Internal Medicine Residency Training Programs affiliated with Harvard Medical School. We examined the development of mentoring relationships during residency training, and measured satisfaction with mentoring and with perceived career preparation.

RESULTS: Of the 329 respondents (65\% response rate), 93\% reported that it is important to have a mentor during residency, but only half identified a current or past mentor. Interns [adjusted odds ratio (AOR) 0.3 (95\% confidence interval (CI) $0.2,0.5)]$ and underrepresented minority residents $[0.3(0.1,0.7)]$ were significantly less likely to establish a mentoring relationship than their peers. Mentored residents were nearly twice as likely to describe excellent career preparation $[1.8(1.1,3.1)]$.

CONCLUSION: Our findings demonstrate the importance of mentoring to medical residents, and identify a relationship between mentoring and perceived career preparation. We also identify a relative lack of mentoring among interns and underrepresented minority residents.

KEY WORDS: mentoring; graduate medical education; faculty development.

DOI: $10.1111 / \mathrm{j} .1525-1497.2006 .00346 . \mathrm{x}$

J GEN INTERN MED 2006; 21:340-345.

(C) 2006 by the Authors

$\mathrm{T}$ here has been a recent focus on explicit competencies to make the educational process in residency training more effective. ${ }^{1}$ With the implementation of reduced work hoursmaking training safer for patients and more humane for residents $^{2,3}$ - experts and panels have recommended strengthening mentoring programs to improve the experience and outcome of residency training. ${ }^{4-9}$ Clearly, an important goal of residency training remains the preparation of young physicians for their future careers in medicine, through a system that enables them to reach their personal and professional goals in service to society. Despite the obvious appeal of better mentoring for residents, few data are available to characterize

The authors have no conflicts of interest to report.

Preliminary findings were presented at the Annual Meeting of the Society of General Internal Medicine, May 2001.

Address correspondence and requests for reprints to Dr. Ramanan: Director of Faculty Development, Center for Health Education, Long Beach Memorial Medical Center, University of California, Irvine, 2801 Atlantic Avenue, Long Beach, CA 90806 (e-mail: rramanan@ memorialcare.org). residents' views of mentors, or to identify characteristics associated with effective mentoring experiences.

Recent studies describe stress ${ }^{10}$ and burnout ${ }^{11}$ during residency training. Discontent expressed by role models and teachers in academic medical centers ${ }^{10}$ may further affect quality of care and teaching, as well as residents' career choices. Little is known about ways to reduce this stress and to encourage personal and professional growth. Mentoring during the early stages of an individual's career has been associated with a higher level of career satisfaction and a higher rate of promotion, both in medical and non-medical fields, ${ }^{12}$ and may encourage personal growth. Mentoring during residency training may also foster the development of professionalism, a core competency as identified by the Accreditation Council for Graduate Medical Education (ACGME), ${ }^{13}$ and has been advocated as a means of enriching contact between residents and faculty physicians. ${ }^{14}$

Successful mentoring relationships may enable faculty to provide career and psychosocial support to trainees, while guiding their development of professional expertise. ${ }^{15-17}$ In a previous study, we found that junior faculty value mentors who maintain close contact while providing counsel on professional decisions and aiding in building professional networks. $^{18}$ However, little is known about mentoring relationships during residency training. Although mentoring relationships between faculty and trainees have been encouraged in order to improve satisfaction with the training experience, and trainee perception of their preparation for their future careers, ${ }^{19,20}$ few data examine the effectiveness of such relationships during residency training. In this context, our aim was to describe mentoring relationships among internal medicine residents, and to examine the relationship between mentoring and perceived career preparation.

\section{METHODS}

\section{Study Site and Population}

We developed a questionnaire about mentoring in residency for use in internal medicine residency training programs at five hospitals affiliated with Harvard Medical School: Beth Israel Deaconess Medical Center, Brigham and Womens' Hospital, Cambridge Hospital, Massachusetts General Hospital, and Mount Auburn Hospital. These residency programs are independent, each with its own program director, administrators, and curriculum. Of the five programs, three have more than 100 residents, and two have fewer than 50 residents. At the

Manuscript received December 1, 2004

Initial editorial decision March 11, 2005

Final acceptance November 14, 2005 
time the survey was conducted, two programs assigned a mentor to all entering residents, one "encouraged" mentoring without formal assignment, and two programs had no system to encourage mentoring.

\section{Questionnaire Development}

Using factors specific to residency training, and a consensus statement on mentoring by the National Academy of Sciences, the National Academy of Engineering, and the Institute of Medicine, ${ }^{21}$ we developed a questionnaire to address our specific aims. We included the following definition at the beginning of the questionnaire: A mentor is an active partner in an ongoing relationship who helps you maximize your potential and achieve your personal and professional goals. We developed questions to examine the importance that residents place on mentoring during residency, whether residents report that their residency program encouraged mentoring, and satisfaction with both global and specific qualities of mentoring.

We included specific items to examine residents' confidence in career decisions, support when faced with uncertainty, and overall satisfaction with the residency program. We further examined barriers to developing a mentoring relationship, and identified qualities associated with satisfying mentorship. Our questionnaire also included items to help us understand details about how mentoring relationships were established and how they were maintained. Examples of such items included whether or not a mentor was assigned by the residency program, and how often the resident was in contact with his/her mentor. We identified factors that were important to residents in choosing a mentor. Response categories consisted of either a 5-point Likert scale, with categories ranging from "strongly agree" to "strongly disagree," or response categories of "yes" or "no." We also included demographic characteristics of both residents and mentors, including age, gender, ethnicity (African American, Asian/Pacific Islander, Caucasian, Indian subcontinent, Latino/a, Native American, Mixed Ethnicity, other), year of training, and career plans (subspeciality, general internal medicine).

We performed pilot testing of the questionnaire with five recent graduates of an internal medicine residency program, and with the five internal medicine residency program directors. Individual response times were recorded, and respondents were interviewed after completing the questionnaire to understand their experiences. The questionnaire was subsequently modified based on these findings to include items that explored personal aspects of the mentoring relationship. The final questionnaire consisted of 58 items, and required approximately 10 minutes to complete.

\section{Questionnaire Administration}

To enlist the support of the program directors, one investigator (RR) met individually with each program director and/or assistant program director to discuss the aims of the study. We obtained the support of each program director before we requested residents to complete our survey. In addition to co-signing an introductory letter with the lead investigator, program directors or chief medical residents sent e-mails and made announcements at teaching conferences to encourage residents to complete the questionnaires.
We mailed questionnaires with cover letters to all Internal Medicine residents in May, 2000, seeking responses based on their experiences over the prior academic year. We sent two additional mailings to nonrespondents. For four programs, we sent material to residents at their home address, and for the fifth program, to their hospital mailbox, based on the preference of the program director. In a cover letter, we assured all residents that the data collected would be confidential and reported only in aggregate form. Residents were also assured that declining participation in this study would not adversely affect their evaluations or other aspects of their residency. To encourage responses, we included participants in a drawing for a $\$ 100.00$ gift certificate to a local restaurant. We excluded residents who did not have a current mailing address listed with the program. Our study procedures and questionnaire were approved by the Committee on Clinical Investigation, the Institutional Review Board (IRB) of the Beth Israel Deaconess Medical Center, as well as by all residency program directors. Data were entered into a Microsoft Access database by a research assistant, and then verified by one investigator (R.R.). To preserve the confidentiality of individual sites, we agreed not to present the number of residents at each site in our results.

\section{Data Analysis}

We compared the demographic characteristics of the study respondents with those of the non-respondents. To understand the epidemiology of mentorship during residency training, we examined the proportion of residents who reported that having a mentor was important during residency, and reported either identifying a mentor or being satisfied with current mentorship. We examined the ideal characteristics of a mentor as identified by each resident. We compared residents who identified themselves as being and not being mentored, looking at differences in confidence regarding career decisions, satisfaction with residency program, and adequacy of career guidance. For these analyses, Likert scale responses were dichotomized into two categories (strongly agree/somewhat agree vs neither agree nor disagree/somewhat disagree/strongly disagree), to identify individuals who expressed any degree of agreement with the item in question.

To assess differences in mentoring experiences by gender, we examined the identification of a mentor, satisfaction with mentorship, and perceived importance of mentorship for men and women. We compared the preferences of male and female residents in their choice of a mentor. We conducted similar analyses to examine differences in the experience of residents who were and were not assigned a mentor. We conducted multivariable analyses to find factors independently associated with identifying a mentor or with being satisfied with mentorship. In addition, we developed separate models to find factors associated with satisfaction with career preparation or career guidance. We included in the model factors that were significant at $P<0.05$, after bivariable analysis. To control for possible confounding, we built models using forward selection. We adjusted for gender and ethnicity, and then added factors of interest (year of training, career plans, and history of prior mentoring) to assess their relation to the outcomes. We determined statistical significance with $\chi^{2}$ tests for dichotomous variables and logistic regression for multivariable analyses. All 
Table 1. Respondent Characteristics $(n=329) *$

\begin{tabular}{lr}
\hline \hline Characteristics & Respondents \\
\hline Sex & \\
Male & $173(53 \%)$ \\
Female & $154(47 \%)$ \\
Ethnicity & \\
Asian or Indian & $80(24 \%)$ \\
White & $205(62 \%)$ \\
Underrepresented minority & $24(7 \%)$ \\
Year of training & $130(40 \%)$ \\
Intern & $198(60 \%)$ \\
Resident & \\
Planned career & $102(31 \%)$ \\
General Internal Medicine & $184(56 \%)$ \\
Subspecialty & $41(13 \%)$ \\
Undecided & \\
\hline
\end{tabular}

* Total may not equal $100 \%$ because of missing data for individual items. For ethnicity, 20 residents reported either mixed ethnicity or had missing data.

'Underrepresented minority (URM) consists of African Americans, Latinos, and Native Americans.

analyses were performed using SAS statistical software (version 8.1, SAS institute, Cary, NC).

\section{RESULTS}

\section{Response Rate and Respondent Characteristics}

Of 507 eligible residents, a total of 329 residents $(65 \%$ response rate) responded to our survey. The response rate ranged from $44 \%$ to $85 \%$ among the five residency programs. Table 1 shows the characteristics of the respondents. Nearly $50 \%$ were women. Fifty-six percent planned a career in a subspecialty, and $31 \%$ planned a career in general internal medicine. Table 2 demonstrates the demographic similarity of respondents among the five study sites. We do not include the number of participating residents at each site to protect the confidentiality of the individual sites. Among the respondents, 111 residents (34\%) belonged to residency programs that assign a mentor, and 218 residents (66\%) were not assigned a mentor by their residency training program. Of $178 \%$ non-respondents, $46 \%$ were PGY $1 \%$, 25\% were PGY $2 \%$ and $29 \%$ were PGY 3. Nonrespondents and respondents were similar in terms of gender and ethnicity.

\section{Description of Mentoring Relationships}

The residents surveyed expressed a clear opinion about the importance of mentoring: $93 \%$ reported that it is important to have a mentor during residency. Only $42 \%$ of all residents were satisfied with mentoring during residency, although 57\% reported that their residency program encouraged the development of mentoring relationships. Approximately one half of the residents identified either a current or prior mentor during residency training (Table 3). Among this group, 60\% felt satisfied with mentoring.

One half of the mentored residents reported that their mentor was assigned to them, either by a residency program director, or through a formal mentorship program. Some residents regarded their continuity clinic preceptor as a mentor. Of the remaining mentored residents, $43 \%$ initiated the relationship, while only $8 \%$ described mentoring relationships initiated by a mentor (Table 3). As shown in Table $3,45 \%$ of mentored residents described contact with their mentor at least once each month, with an additional $41 \%$ in contact with their mentor at least twice a year. Among all mentored residents, the majority reported sufficient contact with their mentor, but a significant minority, 34\%, reported inadequate contact.

\section{Positive and Negative Aspects of Mentoring}

The majority of mentored residents described benefits from the relationship, with $70 \%$ of residents describing a meaningful impact on professional development and 57\% describing a beneficial effect on personal development. The residents also described receiving helpful advice on career decisions (61\%), clinical work (61\%), and research (38\%), with a smaller percentage describing assistance finding a position after residency $(32 \%)$ or guidance when facing disappointment or failure $(25 \%)$. Few negative aspects of mentoring were described, but one in four residents reported discomfort discussing "important issues" with their mentor, and one-seventh described feeling they were an imposition on their mentor. Of residents who did not have mentoring relationships during residency training, one half of residents without a mentor (49\%) had not thought about approaching someone; of the remainder, $19 \%$ had not met someone they would trust as a mentor, and $25 \%$ were afraid to approach a senior colleague about mentorship.

\section{Characteristics of Mentors}

We asked residents to describe their mentors. The majority of mentors were male and white, consistent with the demographic characteristics of the faculty at this medical school (data not shown). Most residents identified a mentor in an academic medical center, usually in their own institution. Nearly onehalf of mentors were faculty in a Division of General Medicine.

Table 2. Respondent Characteristics by Internal Medicine Residency Program*

\begin{tabular}{|c|c|c|c|c|c|}
\hline Program & Female (\%) & Underrepresented Minority ${ }^{\dagger}(\%)$ & PGY 1 (\%) & PGY 2 (\%) & PGY $3(\%)$ \\
\hline A & 43 & 1 & 31 & 32 & 38 \\
\hline $\mathrm{B}$ & 29 & 12 & 41 & 29 & 29 \\
\hline $\mathrm{C}$ & 44 & 14 & 48 & 30 & 17 \\
\hline $\mathrm{D}$ & 60 & 11 & 48 & 29 & 23 \\
\hline $\mathrm{E}$ & 48 & 13 & 44 & 34 & 22 \\
\hline
\end{tabular}

* Number of residents at each site is not given to protect site confidentiality.

'Underrepresented minority (URM) consists of African Americans, Latinos and Native Americans. 
Table 3. Residents' Responses About Mentoring Relationships*

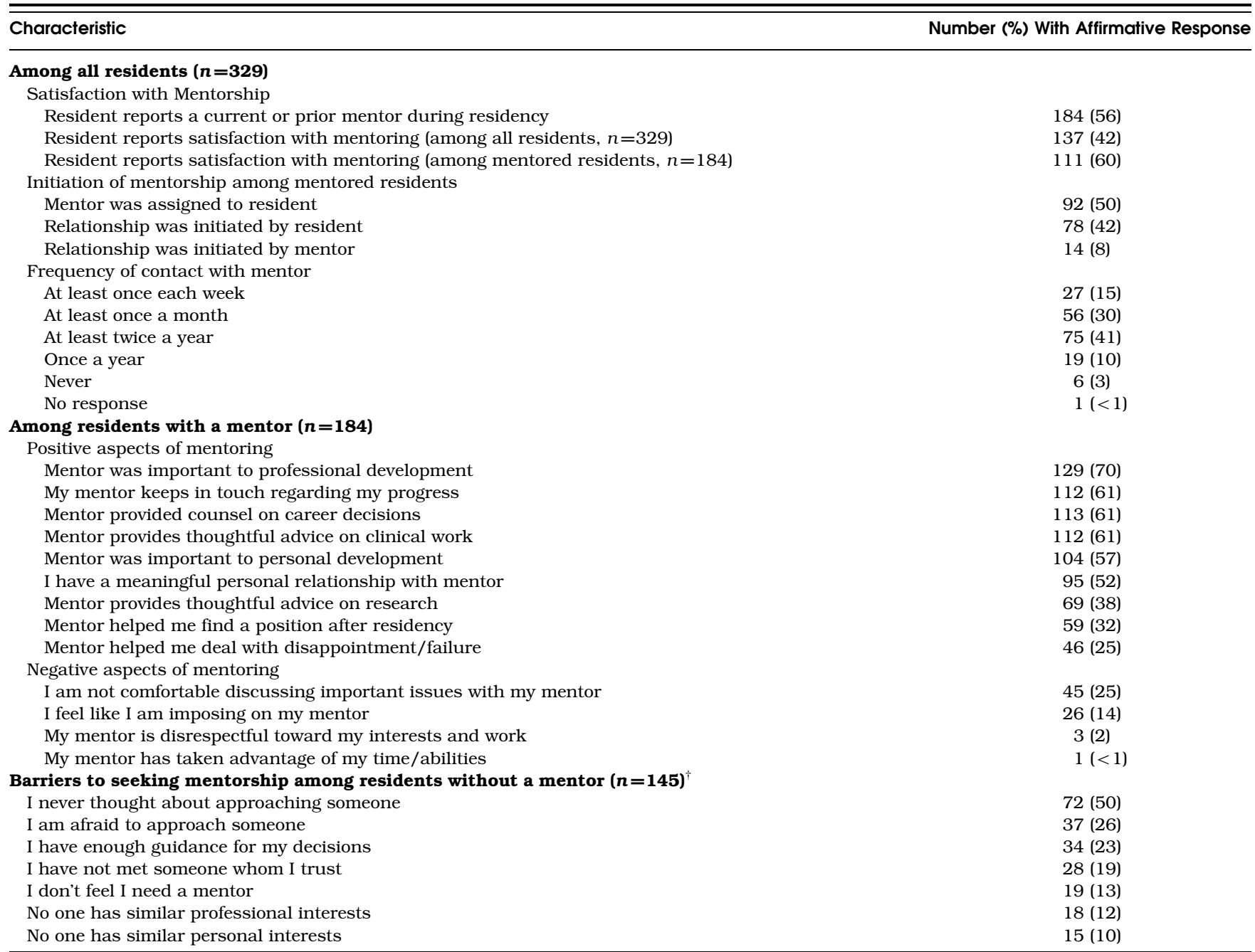

*Total may not equal 100\% due to either nonresponse or multiple responses.

${ }^{\dagger}$ Total exceeds $100 \%$ due to multiple responses.

\section{Identification of a Mentor and Satisfaction with Mentorship}

We examined the factors associated with having a mentor using a multivariable model. Residents who joined a training program that assigned a mentor were significantly more likely to identify a mentor during residency [AOR 8.2, 95\% CI (4.4, $15.4)]$. Interns $[0.3(0.2,0.5)]$, and underrepresented minority residents $[0.3,(0.1,0.7)]$ were significantly less likely to establish a mentoring relationship than their peers. These associations remained significant after adjusting for demographic characteristics, career plans, and a personal history of mentorship in medical school or college (Table 4).

We were unable to identify any characteristics of residents associated with satisfaction with mentorship. Underrepresented minority residents were as likely to be satisfied with mentorship as their colleagues $[0.8(0.2,3.2)]$. House officers in a residency program that assigned a mentor were as likely to be satisfied with mentorship as house officers in residency programs that did not assign a mentor $[1.3(0.7,2.4)]$. Similarly, there was no significant difference in satisfaction with men- torship based on demographic characteristics of the mentor, including mentor gender, ethnicity, or work setting.

Among residents who were mentored, qualities of the relationship significantly associated with overall satisfaction with mentorship in multivariable models were: importance to personal development $[2.7(1.2,6.0)]$; keeping in touch regarding progress $[3.7(1.7,8.3)]$; belief that the resident was not imposing on the mentor [2.8 $(1.2,6.8)]$; and having a mentor who provided thoughtful advice on research $[3.1(1.4,7.2)]$. Qualities that were not significantly associated with satisfaction with mentorship included: providing advice on clinical work, handling disappointment or failure, finding a position after residency, or having a meaningful personal relationship with their mentor.

Finally, when examining the relationship between mentoring during residency and the perception of excellent career preparation (Table 5), we found that mentored residents were nearly twice as likely to describe excellent career preparation [1.8 (1.1, 3.1)]. After accounting for mentorship, neither ethnicity, year of training, mentor assignment by program, nor a history of mentoring were associated with satisfaction with ca- 
Table 4. Factors Associated With Identifying a Mentor Among All Residents $(n=316)^{*}$

\begin{tabular}{|c|c|c|}
\hline Factor & Resident Identifies a Mentor (\%) & AOR $(95 \% \mathrm{Cl})$ \\
\hline \multicolumn{3}{|l|}{ Sex } \\
\hline Female & 57 & $1.2(0.7,2.1)$ \\
\hline Male & 55 & 1.0 \\
\hline \multicolumn{3}{|c|}{ Underrepresented minority } \\
\hline Yes & 46 & $0.3(0.1,0.7)^{* *}$ \\
\hline No & 56 & 1.0 \\
\hline \multicolumn{3}{|c|}{ Year of training } \\
\hline Intern & 45 & $0.3(0.2,0.5)^{* *}$ \\
\hline Resident & 63 & 1.0 \\
\hline \multicolumn{3}{|c|}{$\begin{array}{l}\text { Planned a career in a } \\
\text { subspecialty }\end{array}$} \\
\hline No & 57 & $1.0(0.6,1.6)$ \\
\hline Yes & 54 & 1.0 \\
\hline \multicolumn{3}{|c|}{ Assigned a mentor } \\
\hline Yes & 82 & $8.2(4.4,15.4)^{* *}$ \\
\hline No & 43 & 1.0 \\
\hline \multicolumn{3}{|c|}{$\begin{array}{l}\text { History of mentorship } \\
\text { (in medical school or college) }\end{array}$} \\
\hline Yes & 59 & $1.3(0.8,2.2)$ \\
\hline No & 53 & 1.0 \\
\hline
\end{tabular}

*Adjusted for sex, ethnicity, year of training, mentor assignment, career plans and history of mentorship.

** $\mathrm{P}<0.05$.

$A O R$, adjusted odds ratio; CI, confidence interval.

reer preparation. Of note, female residents were significantly less likely than male residents to describe excellent career preparation $[0.6(0.4,0.9)]$ after adjusting for these factors.

\section{DISCUSSION}

Our findings demonstrate the importance of mentoring to personal and professional development during residency, and the association between having a mentor and the perception of excellent career preparation. Nearly all residents surveyed thought mentoring was important and particularly valued

Table 5. Factors Associated with the Perception of Excellent Career Preparation $(n=315)^{*}$

\begin{tabular}{|c|c|c|}
\hline Factor & Perceive Excellent Career Preparation (\%) & AOR $(95 \% \mathrm{Cl})$ \\
\hline \multicolumn{3}{|l|}{ Sex } \\
\hline Female & 58 & $0.6(0.4,0.9)^{* *}$ \\
\hline Male & 71 & 1.0 \\
\hline \multicolumn{3}{|c|}{ Underrepresented minority } \\
\hline Yes & 58 & $0.9(0.4,2.2)$ \\
\hline No & 66 & 1.0 \\
\hline \multicolumn{3}{|c|}{ Year of training } \\
\hline Intern & 64 & $1.0(0.6,1.6)$ \\
\hline Resident & 67 & 1.0 \\
\hline \multicolumn{3}{|c|}{ Identified a mentor } \\
\hline Yes & 72 & $1.8(1.1,3.1)^{* *}$ \\
\hline No & 57 & 1.0 \\
\hline \multicolumn{3}{|c|}{ Assigned a mentor } \\
\hline Yes & 71 & $1.3(0.7,2.3)$ \\
\hline No & 63 & 1.0 \\
\hline \multicolumn{3}{|c|}{$\begin{array}{l}\text { History of mentorship } \\
\text { (in medical school or college) }\end{array}$} \\
\hline Yes & 65 & $0.8(0.5,1.3)$ \\
\hline No & 66 & 1.0 \\
\hline
\end{tabular}

*Adjusted for sex, ethnicity, year of training, whether they have a mentor, mentor assignment, and history of mentorship.

${ }^{* *} \mathrm{P}<0.05$.

AOR, adjusted odds ratio; CI, confidence interval. mentors who maintained close contact and provided useful career advice. Nearly half the residents surveyed did not have mentors, and among this group fewer were satisfied with mentorship. Residents did not seek mentorship during residency for several reasons including: the fear of approaching a faculty member, inability to find a faculty mentor whom they trusted, and never having thought about approaching a faculty member.

Our study also demonstrates specific aspects of mentoring relationships that may be useful to leaders in medical education who choose to develop mentoring programs for their house staff. We showed that most residents met with their mentor every 6 to 12 months, and that the majority of residents reported this as sufficient. Clearly stating the expected frequency of meeting may reduce faculty concerns about the time commitment involved in mentoring. Although earlier studies have raised questions about the importance of concordance by race and ethnicity between mentors and mentees, ${ }^{22,23}$ we did not detect a difference in satisfaction with mentoring based on resident or faculty characteristics. This may reduce the burden of finding a "perfect match" prior to initiating a mentoring relationship. As advocated by experts, ${ }^{24}$ we encourage residency program directors to dedicate resources to developing senior physicians as mentors, to reward faculty who dedicate their time to mentoring, and to measure the effectiveness of mentoring relationships. ${ }^{25}$

We believe that the relative lack of mentoring that we identified among interns and underrepresented minority residents is a potentially serious problem, as is our finding of female residents' report of less adequate career preparation compared with their male peers. Prior reports have described similar inequities among women and underrepresented minority faculty in achieving effective mentoring. ${ }^{26}$ It has been found, for example, that female residents training in Obstetrics and Gynecology may perceive significant gender differences in mentoring, ${ }^{27}$ and that identifying a mentor may be associated with both resident gender and career goals. ${ }^{28} \mathrm{Al}-$ though our data do not identify differences in mentoring requirements among specific groups of internal medicine residents, we recommend that program directors remain vigilant about these types of disparities.

The focus of our study on internal medicine residencies affiliated with a single medical school may limit the generalizability of our findings, although these residents represent five distinct residency training programs. In addition, although we identified qualities of mentoring relationships that were significantly associated with satisfaction with mentorship, limitations of power may have prevented us from identifying other important relationships. We would advocate conducting a multicenter follow-up study to examine the effect of mentoring on career choices and career satisfaction.

Residency training is a period of remarkable professional growth and meaningful personal development as young physicians acquire clinical and professional skills that will help shape their future career and build (or weaken) important personal relationships. Recent data demonstrate that residency is associated with burnout and stress that impact patient care and personal health. ${ }^{11,12}$ Our findings support the contention that effective mentorship-a relationship whose value has been demonstrated among faculty physicians ${ }^{16,17}$ —is highly valued by residents and can contribute to improved satisfaction with career preparation and their experience of training. We recommend that leaders in Graduate Medical Education 
re-examine the role of mentoring during the critical years of residency training, and facilitate the development of mentoring relationships by considering establishment of mentoring programs, and by rewarding both residents and faculty for their contributions.

We wish to thank the internal medicine residency program directors for their valuable help with this study, and the internal medicine residents who thoughtfully responded to our survey. Dr. Phillips is supported by a National Research Service Award (K24 AT0589-03).

\section{REFERENCES}

1. ACGME Program Requirements for Residency Education in Internal Medicine. Available at: http://www.acgme.org. Accessed February 17, 2004.

2. The ACGME's Approach to Limit Resident Duty Hours: The Common Standards and Activities to Promote Adherence. Available at: http:// www.acgme.org. Accessed February 17, 2004.

3. AAMC Policy Guidance on Graduate Medical Education. Available at: http://www.aamc.org/hlthcare/gmepolicy/start.htm. Accessed February $20,2004$.

4. Murray E, Gruppen L, Catton P, Hays R, Woolliscroft JO. The accountability of clinical education: its definition and assessment. Med Educ. 2000;34:871-9.

5. Spike $\mathbf{N}$, Alexander $\mathbf{H}$, Elliott $\mathbf{S}$, et al. In-training assessment-its potential in enhancing clinical teaching. Med Educ. 2000;34:858-61.

6. Wright SM, Kern DE, Kolodner K, Howard DM, Brancati FL. Attributes of excellent attending-physician role models. $N$ Engl $J$ Med. 1998;339: 1986-9.

7. Sachdeva AK. Preceptorship, mentorship, and the adult learner in medical and health sciences education. J Cancer Educ. 1996;1 1:131-6.

8. Rodney WM. Role models during residency training important. Fam Med. 1994;26:471.

9. Levy BD, Katz JT, Wolf MA, et al. An initiative in mentoring to promote residents' and faculty members' careers. Acad Med. 2004;79:845-50.

10. Collier VU, McCue JD, Markus A, et al. Stress in medical residency: status quo after a decade of reform? Ann Intern Med. 2002;136:384-90.

11. Shanafelt TD, Bradley KA, Wipf JE, et al. Burnout and self-reported patient care in an internal medicine residency program. Ann Intern Med. $2002 ; 136: 358-67$.
12. Schapira MM, Kalet A, Schwartz MD, et al. Mentorship in general internal medicine. J Gen Intern Med. 1992;7:248-51.

13. ACGME Outcome Project. Available at: http://www.acgme.org. Accessed February 20, 2004

14. Reynolds PP. Reaffirming professionalism through the education community. Ann Intern Med. 1994;120:609-14.

15. Bhagia J, Tinsley JA. The mentoring partnership. Mayo Clin Proc. 2000;75:535-7.

16. Jackson VA, Palepu A, Szalacha L, et al. "Having the right chemistry": a qualitative study of mentoring in academic medicine. Acad Med. 2003;78:328-34.

17. Weilepp AE. Female mentors in short supply. JAMA. 1992;267:739-42.

18. Ramanan RA, Phillips RS, Davis RB, et al. Mentoring in medicine: keys to satisfaction. Am J Med. 2002;112:336-41.

19. Galicia AR, Klima RR, Date ES. Mentorship in physical medicine and rehabilitation residencies. Am J Phys Med Rehab. 1997;76:268-75.

20. Masmith L, Boillat M, Rubenstein H, et al. Faculty advisor program for family medicine residents. Can Fam Physician. 1997;43:1257-63.

21. Adviser, Teacher, Role Model, Friend. National Academy Press. Washington DC 1997. http://stills.nap.edu/readingroom/books/mentor. Accessed March 1, 2004.

22. Thomas DA. The truth about mentoring minorities. Race matters. Harv Bus Rev. 2001;79:98-107, 168.

23. Bright CM, Duefield CA, Stone VE. Perceived barriers and biases in the medical education experience by gender and race. J Natl Med Assoc. 1998;90:681-8.

24. Connor MP, Bynoe AG, Redfern N, et al. Developing senior doctors as mentors: a form of continuous professional development. Report of an initiative to develop a network of senior doctors as mentors: 1994-1999. Med Educ. 2000;34:747-53.

25. Berk RA, Berg J, Mortimer R, et al. Measuring the effectiveness of faculty mentoring relationships. Acad Med. 2005;80:66-71.

26. Carr PL, Bickel J, Inui TS. Characteristics of Academic Health Centers: What Does a Young Faculty Member Need to Know? Taking Root in a Forest Clearing: A Resource Guide for Medical Faculty. Boston: Boston University School of Medicine; 2004. Page 19. Available at: http:// www.bumc.bu.edu/Dept/ContentPF.aspx?PageID=8849\&DepartmentID=42. Accessed June 1, 2005.

27. Cain JM, Schulkin J, Parisi V, et al. Effects of perceptions and mentorship on pursuing a career in academic medicine in obstetrics and gynecology. Acad Med. 2001;76:628-34.

28. Reisman AB, Gross CP. Gender differences in the ability to identify a mentor at morning report: a multi-institutional study. Teach learn med. . 2002;14:236-9. 